\title{
An Application of the Contingent Valuation Method to Assess the Efficiency of the Institutional Structure of Irrigation Property Rights: The Case of the Peninsula of Santa Elena, Ecuador
}

\author{
PAÚL A. HERRERA* **, GUIDO VAN HUYLENBROECK ${ }^{* *}$ \& \\ RAMÓN L. ESPINEL** \\ *Department of Agricultural Economics, Ghent University, Ghent, Belgium; **Escuela Superior \\ Politécnica del Litoral, Guayaquil, Ecuador
}

\begin{abstract}
Many of the observed problems of water management in developing countries are linked to inefficient institutional structures of property rights. This is particularly the case with many public irrigation systems that have never achieved the expected social and economic benefits. In this paper it is argued that the Contingent Valuation Method (CVM) can be applied to evaluate the degree of inefficiency of such institutional structure for the case of one of the most important irrigation systems in Ecuador in the Peninsula of Santa Elena (PSE). The procedure applied consists of eliciting an economic value among irrigators. Thus, Willingness to Pay (WTP) questions are used to value a specific outcome of a policy intended to assure the right to have an efficient management of the canals. The evaluation criterion consists of comparing the resulting economic value with the price currently charged to irrigators. Any deviation is considered an economic rent which is wasted. Thus, CVM is used to investigate the potential benefits of a hypothetical change in the existing property rights structure. The estimation results assert that the proposed change would provide positive net benefits to water users in the PSE.
\end{abstract}

\section{Introduction}

A critical point between the field of economics and law is how property rights affect the ultimate use of a particular resource. For many years literature has claimed that under certain well-defined conditions, the assignment of property rights will not affect the ultimate allocation of goods among rational actors (see for example Calabresi \& Melamed, 1972; Landes \& Posner, 1987; Posner, 1992). However, this view has raised some observations. According to Levy \& Friedman (1994) the circumstances under which this applies "may be more limited than is often assumed ..., mainly because the arguments are valid only under very 
restrictive conditions". These conditions are: (i) allocation and redistribution decisions must not affect marginal values; (ii) goods must be freely substitutable; (iii) property rights must be well defined and enforced, and (iv) goods must be fungible. In this respect, few studies have explored the relationship between legal rights and the economic allocation of goods that do not fulfill one or more of these conditions (Levy \& Friedman, 1994).

On the other hand, literature on Contingent Valuation Methods (CVM) gives no clear orientations in how far property rights definition can be a determinant of the economic value of a particular resource. While many theorists concentrate on trying to explain the high observed variance between Willingness to Pay (WTP) and Willingness to Accept (WTA) measures reported in many empirical studies, few have attributed such differences to how property rights are defined or perceived by people in the case of goods with no close substitutes (see mainly Hanemann, 1991; examples of attempts to explain divergences between WTP and WTA on statistical grounds can be found in Randall \& Stoll, 1980; Coursey et al., 1987; Mitchell \& Carson, 1989).

The discussion point raised is therefore whether the economic value of a particular resource is influenced by the institutional structure of property rights involved in the allotment of such a resource. Based on economic principles the answer is 'yes'. However, in the application arena few studies have related their aggregated monetary valuations with the institutional structure of property rights. This becomes particularly cumbersome when the resource has no close substitutes or when there are neither well-defined nor well-enforced property rights as is typically the case in countries such as Ecuador.

In the case of irrigation for agricultural purposes, water is an input for the production process. This means that not only the economic value of the resource is important but also the costs of provision and the current prices, which should in principle be equated one to the other in order to internalize the full range of externalities derived from using water in agriculture. So, economic valuation methods can be used to provide some clues in the difficult task of pricing irrigation water, although as previously discussed such an approach must necessarily consider the underlying institutional structure in order to understand what is being valued and what determines its value.

Given that in the Peninsula of Santa Elena (PSE) irrigation is already priced under a particular institutional structure, economic values can in this case be calculated and used to assess the efficiency of the institutional structure of property rights by means of comparing the estimated value against the current price of water. The hypothesis is that a sub-optimal definition of property rights limits the value people assign to water. People may in fact be willing to pay higher values for having better defined property rights that assure them an optimal provision of irrigation. If this is the case it means that institutional failures in the PSE do not allow internalizing (through price) what users perceive irrigation should be valued at.

This paper is divided into four further sections. The next section describes the research problem. This is followed by a development of the theoretical framework and is particularly related to the valuation method. There is then a development of the economic valuation exercise using CVM and the final section concludes and provides some ideas for further research. 


\section{The Irrigation Problem in the Peninsula of Santa Elena, Ecuador}

The PSE is a coastal area of about $6050 \mathrm{~km}^{2}$. Until the end of the 19th century it was considered an area with high potential for developing agricultural activities. Nevertheless, due to an abrupt deforestation that altered the hydrological cycle, such good conditions changed. Based on information from the National Council for Water Resources (CNRH), 95\% of the original forest of this area has been removed, making the PSE one of the driest areas of Ecuador. The government solution was the construction of a huge Hydraulic Project called the 'Santa-Elena Aqueduct Hydraulic-Project (PHASE)', which was developed by a governmental agency, the Commission for the Development of the Guayas River Basin (CEDEGE). ${ }^{1}$

The different phases of the project began in 1986 and comprise about $120 \mathrm{~km}$ of canals, a tunnel of $7 \mathrm{~km}$, two pumping stations to elevate water $70 \mathrm{~m}$, and three dams with a total storage capacity of 352 million $\mathrm{m}^{3}$. The irrigation capacity of the PHASE has been calculated to be 42000 hectares $^{2}$ with an investment of about US\$580 million, mostly granted by international development organizations by way of foreign debt or contributions (CEDEGE, 2001).

The main goal of the PHASE is to provide water throughout the whole year, solving both the spatial and temporal dimension of the water scarcity problem. The conflicts began when CEDEGE started the construction of the irrigation system, which sparked a sudden interest in buying land under the influence of the canals. Not only farmers but also particularly speculators took advantage of both the misinformation on the value of those lands and the confusing legal framework regarding the property of land by the communes. The final outcome is that after 8 years of operation of the canals less than 6000 ha are being cultivated and there are huge problems ensuring the sustainability of the PHASE operation, and therefore agricultural activities.

Regarding the peasants-commoners of the PSE, their main characteristic is their communal organization whose predominant feature is the communal ownership of land. ${ }^{3}$ They are still considered the largest population group and possessed approximately $85 \%$ of the land before the construction of the irrigation system. Today, it has been calculated that $90 \%$ of that land has been sold, leaving the commoners with the unproductive land and without possibilities for development. Therefore, even though water was considered the key limiting factor for the development of these communes, in terms of CEDEGE's current policy it became a resource available for those who can pay its price.

On the other hand, water policy is not well defined and in general there are no incentives to improve the situation. CEDEGE is not recovering the cost of the infrastructure and farmers are neither well organized nor convinced of taking part in the operation and maintenance (O\&M) activities jointly with CEDEGE. Table 1 shows some figures regarding the predicted capacity of the PHASE and the current supply of water as well as the distribution of irrigators per irrigation zone. Although commoners appear to make up a great percentage of the total users, the proportion of land they hold is minimal. On average a commoner possesses 1 to 2 ha while single private farmers can hold in some cases up to 1000 ha.

\section{Property Rights and Economic Valuation}

Given that markets rarely reflect economic values for most of the environmental 
Table 1. Irrigation potential (current and predicted) and registered users per irrigation area

\begin{tabular}{lccccc}
\hline Irrigation zone & $\begin{array}{c}\text { Predicted } \\
\text { capacity (ha) }\end{array}$ & $\begin{array}{c}\text { In } \\
\text { operation (ha) }\end{array}$ & $\begin{array}{c}\text { Under } \\
\text { construction (ha) }\end{array}$ & $\begin{array}{c}\text { Registered } \\
\text { users }\end{array}$ & Commoners \\
\hline Chongón - Playas & 15691 & 15691 & 0 & 367 & 120 \\
Azúcar - Sube y Baja & 27113 & 4728 & 1200 & 107 & 34 \\
Total & 42804 & 20419 & 1200 & 474 & 154 \\
\hline
\end{tabular}

Source: CEDEGE.

goods, researchers turned to non-behavioural methods for valuing resources, in particular survey methods such as CVM. However, there is considerable controversy over whether CVM adequately measures people's WTP for nonmarketed goods. Besides the problems that can arise from questionnaire design and sampling procedures, the main problem is the observed difference between WTP and WTA found in many empirical studies, which in theory should be very close. Many researchers have documented this variability and investigated its causes (see e.g. Mitchell \& Carson, 1989) but none has been completely successful (Levy \& Friedman, 1994).

However, from the previous discussion it is clear from economic principles that economic values will vary as property rights change, so the interpretation of values requires taking into account the underlying property rights structure involved in the WTP-CV elicitation question. That is, if people view themselves as the owners of a resource, valuation estimates will be much higher than if people believe others own the resource. Thus, WTA and WTP questions imply different perceptions of property rights with respect to the resource involved: WTA suggests that people (respondent) own the resource, while WTP suggests they do not. So, CVM practitioners, in trying to keep the conventional perspective that property rights should have little effect on values, have shown relatively little recognition of these implications. It is clear, however, that WTA-WTP divergences may demonstrate that for less substitutable goods, including various public goods, values vary as property rights definition changes (see for example Levy \& Friedman, 1994; Horowitz \& McConnell, 2000; Arcuri, 2002).

The strategy followed in this paper is to undertake an economic valuation exercise that intentionally implies a change (through the wording of the WTP question) in the property rights structure of irrigation in the PSE. Thus, given that irrigation water is priced, on average, at US\$0.035 per $\mathrm{m}^{3}$, the WTP-CV question is expected to yield a higher aggregated value. This higher value would demonstrate that marginal improvements in the structure of property rights are valued positively by irrigators in the PSE. This in turn implies that the underlying institutional structure is not efficient, given that it does not allow maximizing welfare because of the rents that are not being internalized and used to finance such improvements.

Based on Vermillion (1999), Table 2 provides a list of the bundle of property rights related with the provision of irrigation for the specific case of the PSE and also a brief evaluation of five desirable characteristics property rights should have. These are exclusivity, transferability, durability, enforceability and flexibility. In 


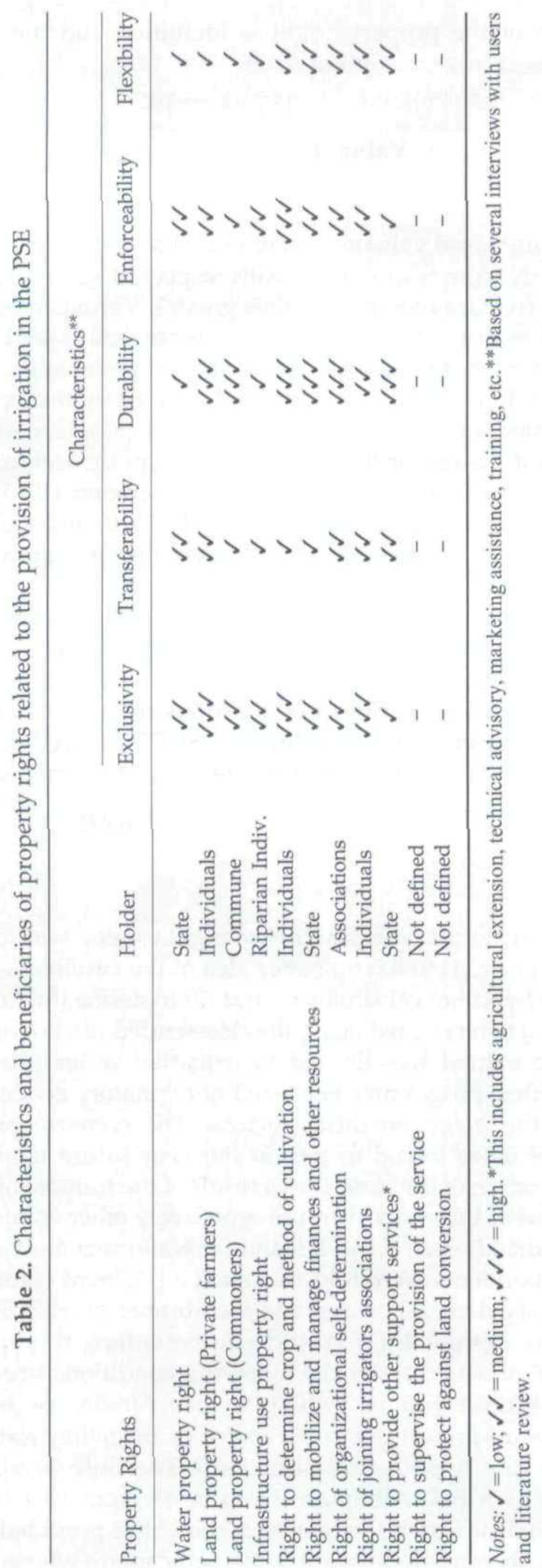


each case the holder of the property right is identified and the level of each characteristic is assessed in a three-point scale.

\section{Application of the Contingent Valuation}

\section{The Method}

CVM is a questionnaire-based valuation-technique that is used to obtain WTP or WTA measures directly from respondents with respect to specific goods, mainly non-marketed goods (environmental or public goods). Various question formats have been developed and used by economists (for more details see Holvad, 1999). Two approaches are used in this paper: (1) the single-bounded approach, which in fact is the same as the close-ended format first introduced by Bishop \& Heberlein in 1979, where pre-tested values of WTP are used to ask people to accept or reject ('yes' or 'no') proposed values for the resource in a hypothetical market; and (2) the double-bounded approach first proposed by Hanemann (1985) and Carson (1985) and applied for the first time by Carson et al. (1990) and Hanemann et al. (1991). In this approach a second question follows the first question, eliciting specific values to which they can only respond 'yes' or 'no'. The amount presented in the second bid depends on the response to the first bid: a lower amount if the answer is 'no' and a higher amount if the answer is 'yes'. Thus, if somebody answers 'yes' to one of the questions and 'no' to the other, this provides both upper and lower bounds of WTP. Blocks of questions are normally introduced in the questionnaire to confirm given values of WTP as well as to provide socioeconomic information (income, gender, age, etc.) or specific characteristics of the respondents.

\section{The Survey}

In a first stage an exploratory research among farmers was developed to accomplish two objectives: (1) to have a better idea of the variables affecting WTP in order to define the hypothetical situation; and (2) to define the range of values of WTP (the price tiers) to be elicited using the close-ended (dichotomous) format.

The resource to be valued was limited to irrigation water provided by the PHASE. The hypothetical programme consisted of regulatory actions intended to increase the use of the irrigation infrastructure. The scenario presented was described in terms of users forced to pay in the near future the total costs of maintenance and operation of the canals (as a result of the transfer of the Property Right related to the use of the system) and progressively other components of the costs (currently subsidized) even if the demand for water remains the same in the future. However, respondents were told that such a payment could be equal or even lower if everybody demands water and the number of users is increased.

Two questions were designed: (1) Would you be willing to pay $\$$ (price) per cubic metre of irrigation water under the following conditions (the hypothetical situation)?; and (2) Would you be willing to pay $\$$ (twice or half the price depending on the last response) per cubic metre of irrigation water under the following conditions (the hypothetical situation)? The only accepted answers were 'yes' or 'no' to each bid. Although it can be thought that such question format implies marginal valuations, irrigation in the PSE is provided and charged on a volumetric basis, the unit of measure being cubic metre whose price is fixed 
for any demanded quantity, thus making irrelevant whether or not the valuation is done per cubic metre or for the total demand per irrigator. In fact, whichever unit of measure is used, the concept of total economic value implies that a total value (use and non-use values) is being elicited, which can be expressed in terms of marginal units of the resource. More important, however, is the fact that respondents in the PSE are very familiar and confident of expressing their perceptions of value in cubic metres. Even so, increasing emphasis is being put on the importance of collecting marginal values rather than total values in CVM surveys (for more details see for example Bulte \& Van Kooten, 1999).

WTP values were stratified after the exploratory research on three levels as follows: $\$ 0.02$ (\$0.01; \$0.04); \$0.04 (\$0.02; \$0.08); \$0.08 (\$0.04; \$0.08) where the values in parenthesis are the lower and higher bounds for each bid. The bid amount varied among the respondents. The analysis proceeds on the assumption that each individual has a maximum willingness-to-pay and that such WTP values have a probability distribution in the population with a defined distribution function.

Sixty surveys were completed by direct interview between September and December of 2002. The pre-test stage was carried out with about 20 farmers, mostly by telephone. In terms of the area surveyed it is about 3000 ha, which is almost half of the area with agricultural production under the influence of the PHASE. Just considering the active farmers, such a sample size implies a sampling error of about $5 \%$ for a $95 \%$ confidence interval. Noting that the total population of users consists of about 470 people, of which only $65 \%$ are active farmers (therefore water users) this sample size implies that about $20 \%$ of the total population of water users' were interviewed.

\section{Contingent Valuation Results}

Single-bounded approach. The economic foundation of CVM implies that two variables must be included as explanatory variables in order to be consistent with a Random Utility Maximization (RUM) model: ${ }^{4}$ (1) a measure of income, which in this case is the Gross Annual Income (GAI) for each unit of production in hundreds of thousands of dollars; and (2) the price bid proposed to each respondent (ELI). The selection of the appropriate model was made using three criteria which are mentioned in order of importance:

1. Improvements in the value of the likelihood function;

2. Improvements in the values of three selected information criteria: the Akaike, the Schwarz and the Hannan-Quinn criterion (for more details see Grasa, 1989); and

3. Improvements in the percentage of correct classification of responses based on predicted probabilities.

An extended model including several variables was first run in order to arrive at a consistent model. Removal of variables was controlled based on the interaction of the proposed criteria and on the requirements of the RUM specification. The resulting model includes the following variables: (1) predominance of permanent crops (PERMCR) in the unit of production (' 1 ' if permanent crops are predominant and ' 0 ' if otherwise); and (2) the proportion of land use (PROPUSE) as a percentage of the total area of the farm. The first variable was frequently 
Table 3. Single bounded WTP coefficients estimation

\begin{tabular}{lcc}
\hline Variables & Coefficients & Means of variables \\
\hline Constant & $13.636(2.369)^{* *}$ & - \\
Bid price (ELI1) & $-205.381(43.04)^{* *}$ & 0.042 \\
Predominance of permanent crops (PERMCR) & $-3.681(0.377)^{* *}$ & 1.60 \\
Proportion of use (PROPUSE) & $7.485(0.923)^{* *}$ & 0.55 \\
Gross annual income (GAI) & $-1.367(0.225)^{* *}$ & 1.09 \\
Log likelihood: $-11.863 ;$ LR Statistic (4df): 49.577; Probability of LR: 0.000 & \\
Info criterion (minimum values) Akaike: 0.56 ; Schwarz: 0.736637 ; Hannan-Q: 0.6303 \\
Percentage of correct classifications: $88.3 \%$; Percent gain from default (constant probability) \\
specification: $61.11 \%$ \\
Nagelkerke R square=0.797; McFadden R-squared $=0.676326$ \\
Goodness of fit: H-L Statistic=1.0343, prob (Chi-Sq-8df)=0.9980; Andrews Statistic (grouped by \\
ELI)=0.0485, prob (Chi-Sq-3df): 0.9972
\end{tabular}

Notes: *Significance: $p<0.05$; ${ }^{* *}$ significance: $p<0.1$; ${ }^{* * *}$ significance $p<0.15$

mentioned during the qualitative research as a key factor because of its relation with the risk and the extent of the investments needed.

Note that the CV model does not impose any particular restriction on the selection of other variables for the model except for the two already mentioned. However, it was found that the logistic specification of the distribution of probability does, although in terms of minimizing the resulting number of variables depending on the number of observations. So, given the limitations on the sample size, the procedure followed consisted of running several regressions to test for the best explanatory power of the model with the lowest number of variables. The single-bounded logit analysis uses as dependent variable the acceptance ('yes $=1$ ') or rejection ('no $=0$ ') to the first bid amount. Table 3 shows the results of the econometric model for the single-bounded approach. A first look at the results shows that all the signs of the coefficients give the correct expected effect to the dependent variable except for GAI, which will be discussed later. All the coefficients are significant at $5 \%$.

The interpretation of the coefficients in this case is not straightforward as in linear regression. In fact, a direct evaluation of the coefficients in the regression equation yields the $\log$ of the odd ${ }^{5}$ between a 'yes' and a 'no' response, which is called a logit. The logistic coefficients are interpreted as the change in the log odds associated with one-unit change in the independent variable. Thus for a respondent facing a price bid of US\$0.02, a predominance of permanent crops (1), a proportion of land use of about $55 \%$ and a gross annual income of US $\$ 110000$, the probability of accepting the bid is almost $100 \%$. In this case, the odd is 123.4 and the log odd 4.8155 . These lasts results come from evaluating the logit function: estimated prob ('yes') $=1 /(1+\mathrm{e}-\mathrm{z}$ ), where $\mathrm{z}=\mathrm{b} 0+\mathrm{b} 1 \times 1+\mathrm{b} 2 \times 2$ ... ; However, if the price bid is increased by 1 cent to 0.03 keeping other variables constant, the new odd and log odd are respectively 15.82 and 2.76 . The difference between these $\log$ odds is exactly 100 times the value of the coefficient (205.38), that is 2.05 . This means that increasing the price bid by 1 cent, the log odd is reduced by a factor of about 2.05. So, for example, for a price bid of US\$ 0.04 , its probability of being accepted is about $66 \%$. This result is consistent with the RUM 


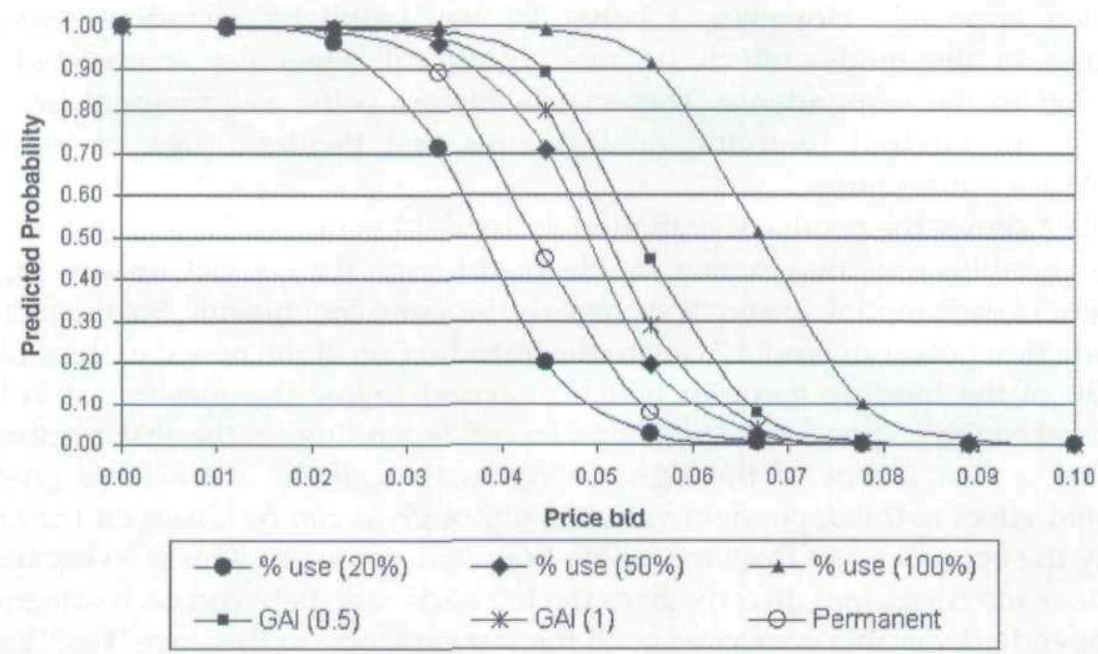

Figure 1. Predicted probabilities of accepting the price bid for different scenarios of land use and income

assumption which states that the demand function must slope downward for the planned change over the resource. This also confirms that the responses are consistent with a canonical model which states that improvements on welfare are valued positively. Similar analysis can be done for the rest of variables.

The coefficient for GAI implies that when income increases for example from US $\$ 110000$ to US $\$ 200000$, the probability of accepting the price bid decreases from $66 \%$ to $34 \%$ changing the log odds by a factor of about 1.367 . Although there is no theoretical reason for this coefficient to be negative, an explanation can be found in the low dependence of some farmers' economy on agriculture as a main source of income. Figure 1 shows some interactions in terms of the probability of accepting the bid against the price bid in dollars per cubic metre for different scenarios of land use and income.

For the logit probability model, Hanemann (1984) provides formulas to aggregate values of WTP based on the estimated coefficients. Those formulas are available for the unrestricted expected value, the median, and the truncated expected value, which restricts WTP to be positive. To proceed with this, an augmented coefficient was first calculated for the model denoted by $\beta_{a}$ which results from evaluating the coefficient estimates at the means of the independent variables except for the coefficient of the bid price which is denoted $\beta_{\mathrm{bp}}$. The augmented coefficient (only considering the significant variables) is 10.39 . So, the mean $(\mathrm{E}(\mathrm{WTP}))$ for $-\infty<\mathrm{WTP}<\infty$, which in turn equals the median WTP is calculated by the ratio $\beta_{\mathrm{a}} /-\beta_{\mathrm{bp}}$. This ratio resulted in an aggregated value of US $\$ 0.05$ per cubic metre of irrigation water. On the other hand, the truncated mean, $(\mathrm{E}(\mathrm{WTP}))$, for $0<\mathrm{WTP}<\infty$ is calculated by the following formula: $\ln (1+\exp$ $\left.\left(\beta_{\mathrm{a}}\right)\right) /-\beta_{\mathrm{bp}}$ which resulted in a similar aggregated value of WTP.

Double-bounded approach. A multinomial logistic regression for different scenarios of WTP responses was done using the same variables of the single- 
bounded approach. However, a better fit was found by including two new variables in the model which became significant when the second bid was proposed to the respondents. These variables are water requirement per year (WREQ) in hundred thousand cubic metres and the total area of the farm (TOTAREA) in hectares.

Table 4 shows the results of both models: model 1 (same variables) and model 2 (same variables plus two extra variables). Although the coefficients are slightly different in each model, the analysis reveals the same conclusions. So, the increase in prediction power of model 2 due to the introduction of the new variables can be a result of the bidding game in which a second follow-up question of WTP is proposed to the respondents (higher or lower depending on the first response).

Again, a first glance of the signs indicates that all the coefficients give the expected effect to the dependent variable, although as can be observed they have exactly the opposite sign from the single-bounded approach. This is so because in this case each coefficient directly gives the log odds ratio between each category of the dependent variable compared with the last category, in this case 'Yes' 'Yes' to the sequence of WTP questions. That is, each coefficient gives us the log odd ratio of having answered ' $N N^{\prime}$ ', ' $N Y^{\prime}$ ', and ' $\mathrm{YN}$ ' versus having answered ' $\mathrm{Y}$ ' if all independent variables are held constant.

The values for the price bid in model 2 indicate the impact of one-unit increase on it over each log odd ratio. The positive effects in this case show that when the initial price bid is increased in one unit, then the probability of answering each of the following options ' $N N^{\prime}$, ' $N Y^{\prime}$, ' $\mathrm{YN}$ ' is also increased compared with a ' $\mathrm{Y}$ ' answer. The strongest effects are for NY (233.10) and NN responses (152.32) and the weakest for YN (67.58). For the case of the predominance of permanent crops the strongest effect is for NY (5.386) which means that having answered like this, compared with a YY response, the probability is increased when the crop pattern is changed to one with predominance of permanent crops. Roughly speaking, this means that when such a crop pattern is changed it is more likely to have a NY answer compared with a YY response. A similar analysis can be done for the rest of variables. Figure 2 shows the behaviour of the multinomial responses for different levels of price bid in dollars per cubic metre.

Using again the formulas to aggregate values of WTP based on the estimated coefficients, the results are as follows: the augmented coefficient for model 1 is -6.4504 and -6.7352 for model 2 . Thus, the mean (E(WTP)) for $-\infty<\mathrm{WTP}<\infty$, which in turn equals the median WTP, is calculated by $\beta_{\mathrm{a}} /-\beta_{\mathrm{bp}}$. This ratio results in an aggregated value of US\$ 0.049 per cubic metre of irrigation water for model 1 and US\$0.045 for model 2. The truncated mean, (E(WTP)), for $0<\mathrm{WTP}<\infty$ resulted in more or less the same values. These results are slightly lower compared with the results from the single-bounded approach; however they can be considered more reliable given the improvement of statistical efficiency by using the doublebounded approach.

\section{Discussion}

As expected the resulting aggregated value of WTP is higher than the current water price (US\$0.035 per cubic metre in average) which means that the gain in efficiency due to the public provision of irrigation under the conditions of the hypothetical situation are wasted rents. This confirms the hypothesis of an 


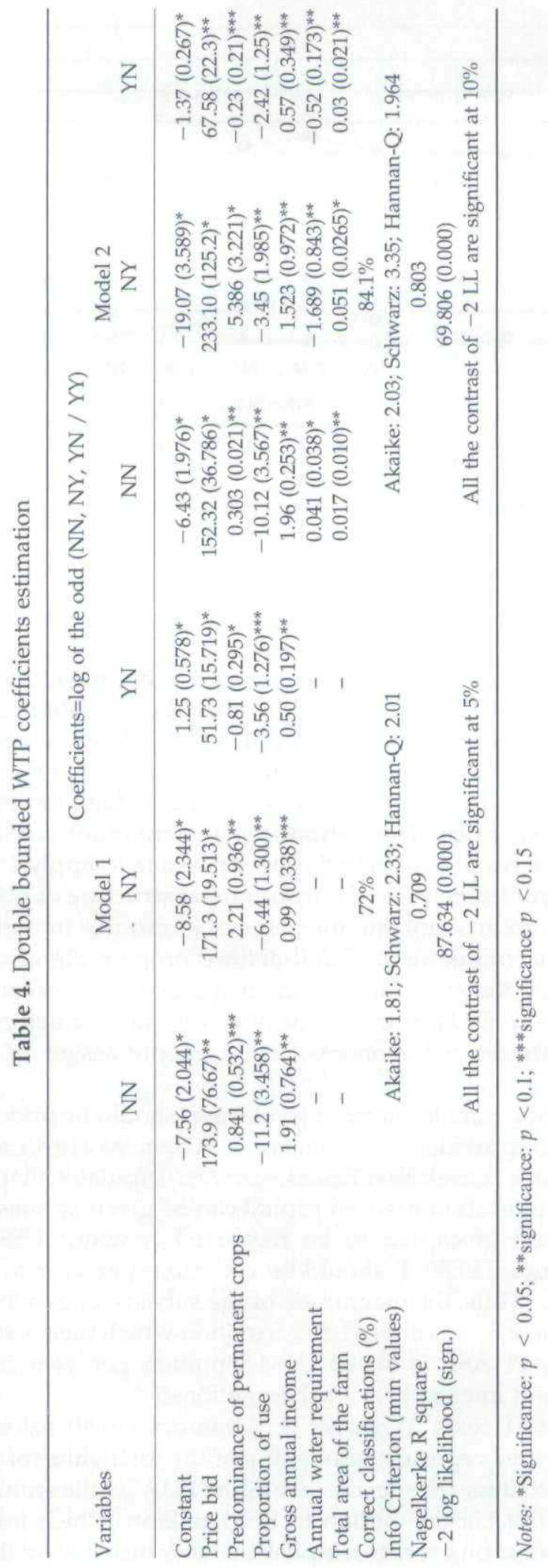




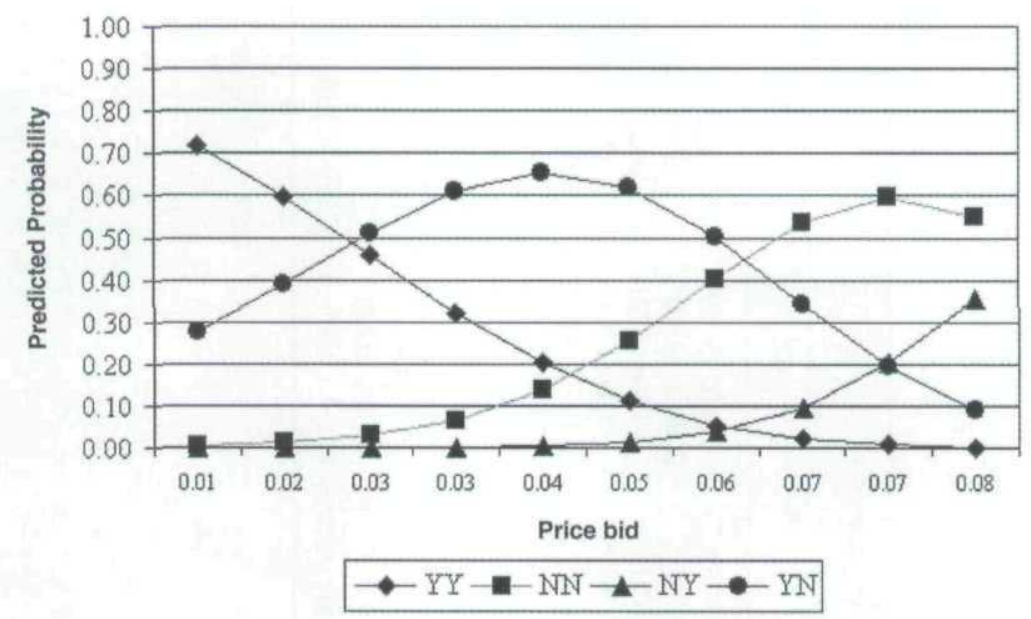

Figure 2. Predicted probabilities of accepting the price bid for different scenarios of responses

inefficient institutional structure of water allocation for the specific case of the PSE.

It is important to note that such a value does not cover yet the full cost of provision of irrigation. Remember, however, that the valuation exercise only valued a hypothetical change in one of the rights of the whole bundle of property rights involved in allocating water for agriculture in the PSE; in this case the one related with the use of the infrastructure. Even so, the value found is about $40 \%$ higher than the current price. This introduces an important consideration for future CV studies. The results indicate that it is possible to apply CVM to value marginal WTP for partial changes in the institutional structure of property rights of a specific resource. So, maximizing the value of a resource by introducing the correct incentives in an environment of well-defined property rights can be a more useful approach for $\mathrm{CV}$ than just calculating an aggregated monetary value. The challenge, therefore, is to find out what type of institutional structure (regime) of property rights maximizes the economic value people assign to a particular resource.

However, the question remains at what level water should be priced in the PSE. Using some guidelines provided by Whitaker \& Alzamora (1990) the following estimations can be made. Given that Ecuadorian law stipulates that $25 \%$ of total investment (US\$580) plus all interest on capital can be given as subsidy to water users, the real amount of capital to be recovered is about US\$450 million. Therefore the minimum CEDEGE should be collecting per year to redeem this value is US\$6 million. ${ }^{6}$ Thus, the magnitude of the subsidy due to interests (with an annual interest rate of $1 \%$ ) is about US\$2.5 million which means that so far the subsidy given to the PHASE is about US\$4.5 million per year including the subsidies on capital and interest previously mentioned.

With respect to O\&M costs, Whitaker \& Alzamora (1990) calculate that on average for Ecuador, they represent about $10 \%$ of the total value of an irrigation system. ${ }^{7}$ This implies that for the specific case of the PHASE, the annual O\&M cost could be in the range of US\$0.8 million to US\$1 million, which for the current demand of water ( 5500 ha on average) implies that less than $50 \%$ of the O\&M cost 
is being recovered. This latter figure was calculated considering the current price of US\$0.035 per cubic metre and an annual water requirement of $2000 \mathrm{~m}^{3}$ per hectare. ${ }^{8}$ Nonetheless, if the price is increased to US $\$ 0.05$, about $70 \%$ of such cost would be recovered. Even so, total subsidies still account for about $94 \%$ of the full cost of provision of irrigation which is almost equal to the average reported by Whitaker \& Alzamora (1990) of $95.8 \%$ for Ecuador. The problem is that only a price of about 60 cents per cubic metre, given the current water demand, would pay such cost. However, if full use of the PHASEs' capacity is assumed with a price of US\$0.05 per cubic metre, about $60 \%$ of the total cost would be recovered as well as $75 \%$ of the O\&M cost. Therefore, a sound policy would be to strengthen the property rights that force land owners to demand water from the PHASE at a price of US $\$ 0.05$ per cubic metre in order to internalize the externality produced by those who are not using water.

\section{Conclusions}

- Irrigation in PSE is framed in a very weak institutional structure where attributions are not well defined and in general incomplete contracts allow users become involved in opportunistic behaviour like the low use of irrigated land.

- The so far 'free' government investment has created the impression that the irrigation system of the PSE belongs to the government and therefore it is their responsibility to operate and maintain the canals. This assistance has certainly discouraged farmers from placing more risk in their investments in the PSE.

- Given that pricing water has been the only water-allocation policy-tool used by CEDEGE and prices are not calculated on a technical basis, there is a deviation between prices and values that explain in some degree the limitations of the current functioning of the institutional structure of property rights in the PSE to get maximum benefits from allocating water in agriculture. The inefficiency is revealed by the higher observed WTP of irrigators for an improved property right that assures them an optimal provision of irrigation under the circumstances of the hypothetical situation formulated in the CV questionnaire.

- A favourable point is that the hypothetical programme proposed is valued at US\$0.015 per cubic metre over the current price of US\$0.035, which means that the programme is considered an improvement and could be considered an objective for future policy-design for this specific case.

- Results of WTP of users in the PSE are very sensitive. This can be interpreted as a poor commitment of users with the irrigation problem in the PSE. This may be due to the fact that the current allocation of property rights impedes users from having a more active role in the integrity of the transaction and also limits the power of CEDEGE as a regulator to intervene in the allocation of water and land. There is, therefore, an urgent need to deepen the analysis of institutional choices for both water and land.

\section{Acknowledgements}

The authors wish to thank the Vlaamse Interuniversitaire Raad (VLIR) - IUC programme at Escuela Superior Politécnica del Litoral (ESPOL) for the funds and all the facilities provided to develop this research. 


\section{Notes}

1. Its creation in 1967 was recommended by the Department of Natural Resources of the Organization of American States, which declared the Guayas River Basin as one of the areas with highest potential for agricultural development in the country.

2. The PHASE in turn utilizes water stored in the Daule-Peripa reservoir for both irrigation and drinkable water throughout the PSE. The water is pumped from the lower Daule River near La Toma in the Guayas province. It goes up $75 \mathrm{~m}$ to an aqueduct which carries it to the Chongón dam where the distribution to the PSE starts,

3. They are considered the historic prolongation of the Manteño-Huancavilca society during the colonial era. A commune is a socio-political unit identified with a particular territory. Each commune has both deliberative and participative instances through its main political organization: the general assembly.

4. This is a stochastic component representing the link between both the economical and the statistical model.

5. The odd of an event occurring is defined as the ratio of the probability that it will occur to the probability that it will not.

6. The law foresees that investments in irrigation should be recovered in 75 years.

7. This estimation is based on 35 irrigation projects already built in Ecuador. This cost includes water management, irrigation management, central management and institutional planning.

8. This water requirement is appropriate for mangoes, which represent about $40 \%$ of the total cropped area in PSE.

\section{References}

Arcuri A. (2002) A different reason for 'de-coasing' environmental law and economics, in: Proceedings of the 19th Annual Conference of the European Association of Law \& Economics, Athens, University of Athens, 19-21 September 2002.

Bishop, R. \& Heberlein, T. (1979) Measuring values of extra market goods: are indirect methods biased? American Journal of Agriculture Economics, 61(5), pp. 926-930.

Bulte, E. H. \& Van Kooten, G. C. (1999) Marginal valuation of charismatic species: implications for conservation, Environmental \& Resource Economics, 14(1), pp. 119-130.

Calabresi, G. \& Melamed, A. (1972) Property rules, liability rules and inalienability: one view of the cathedral, Harvard Law Review, 85, pp. 1089-1128.

Carson, T. (1985) Three essays on contingent valuation (welfare economics, non-market goods, water quality), PhD Dissertation, Department of Agricultural and Resource Economics, University of California, Berkeley.

Carson, T., Hanemann, M. \& Steinberg, D. (1990) A discrete choice CV: estimate of the value of Kenai King salmon, Journal of Behavioral Economics, 19(1), pp. 53-68.

CEDEGE (2001) Basic information about the capacity of the canals and irrigation infrastructure in the Peninsula of Santa Elena.

Coursey, D., Hovis, J. \& Schulze, W. (1987) The disparity between WTA and WTP measures of value, The Quarterly Journal of Economics, 102(3), pp. 679-690.

ESPOL \& CEDEGE (2001) Results of a survey run in a research project supported by the Ministry of Agriculture of Ecuador. Program for the Modernization of Agricultural Services (PROMSA).

Grasa, A. A. (1989) Econometric Model Selection: A New Approach (Dordrecht: Kluwer Academic Publishing).

Hanemann, W. (1984) Welfare evaluations in contingent valuation experiments with discrete responses, American Journal of Agricultural Economics, 66, pp. 332-341.

Hanemann, W. (1985) Some issues in continuous and discrete-response contingent valuation studies, Northeastern Journal of Agricultural Economics, 14, pp. 5-13. 
Hanemann, W. (1991) Willingness to Pay and Willingness to Accept: how much can they differ? American Economic Review, 81(3), pp. 635-647.

Hanemann, W., Loomis, J. \& Kanninen, B. (1991) Statistical efficiency of double-bounded dichotomous choice contingent valuation, American Journal of Agricultural Economics, 73(4), pp. 1255-1263.

Holvad, T. (1999) Contingent Valuation Methods: possibilities and problems. Working paper, University of North London.

Horowitz, J. K. McConnell, K. E. (2002) A Review of WTA/WTP studies, Journal of Environmental Economics and Management, 44(3), pp. 426-447.

Landes, W. \& Posner, R. (1987) The Economic Structure of Tort Law (Cambidge, MA: Harvard University Press).

Levy, D. \& Friedman, D. (1994) The revenge of the Redwoods? Reconsidering property rights and the economic allocation of natural resources, The University of Chicago Law Review, 61, pp. 493-526.

Mitchell, R. \& Carson, R. (1989) Using Surveys to Value Public Goods: The Contingent Valuation Method (Washington DC: Resources for the Future).

Posner, R. (1992) Economic Analysis of Law, 4th edn (Boston: Little, Brown and Company Publishing).

Randall, A. \& Stoll, J. (1980) Consumer's surplus in commodity space, American Economic Review, 70(3), pp. 449-455.

Vermillion D. (1999) Property rights and collective action in the devolution of irrigation system management, in: Proceedings of the International Conference, Collective Action, Property Rights and Devolution of Natural Resource Management, Philippines, 21-25 June 1999 (Feldafing, Germany: Deutsche Stiftung für Internationale Enticklung/Zentralstelle für Ernährung und Landwirtschaft (DSE/ZEL).

Whitaker, M. \& Alzamora, J. (1990) Agriculture \& Economic Survival: The Role of Agriculture in Ecuador's Development. Westview special studies in Social, Political and Economic Development (Colorado: Westview Press Inc.). 
Copyright of International Journal of Water Resources Development is the property of Carfax Publishing Company and its content may not be copied or emailed to multiple sites or posted to a listserv without the copyright holder's express written permission. However, users may print, download, or email articles for individual use. 